\title{
Schwannoma of Hypoglossal Nerve Origin in the Upper Neck: Case Report and Review of the Literature
}

\author{
Yoshihiro Morita ${ }^{1,2}$, Chisato Kawakita3, Misako Taya1,3, Keiko Yuzaki', \\ Takahisa Kotani' ${ }^{1}$, Takaki Iwagami1 ${ }^{1,2}$, Kazuyo Kobayashi' ${ }^{1}$, Nobuo Morita1,3* \\ ${ }^{1}$ Department of Oral and Maxillofacial Surgery, Seichokai Hannan City Hospital, Hannan, Japan \\ ${ }^{2}$ Department of Oral and Maxillofacial Surgery II, Osaka University Graduate School of Dentistry, Osaka, Japan \\ ${ }^{3}$ Department of Oral-Maxillofacial Surgery, NS Medical \& Healthcare Service General Incorporation Foundation, \\ Wakayama, Japan \\ Email: ${ }^{*}$ n-morita-kiefer@jtw.zaq.ne.jp
}

Received 5 June 2014; revised 21 July 2014; accepted 3 August 2014

Copyright (C) 2014 by authors and Scientific Research Publishing Inc.

This work is licensed under the Creative Commons Attribution International License (CC BY).

http://creativecommons.org/licenses/by/4.0/

(c) (i) Open Access

\section{Abstract}

Schwannomas originating from the hypoglossal nerve are extremely rare neoplasms. Hypoglossal schwannomas usually occur between the third and fifth decades of life, with no sex predilection, commonly presenting as a painless, slow-growing, and lateral neck mass. The best treatment is complete surgical excision with preservation of the neural pathway, if possible. In fact, since these tumors are almost always benign, a conservative surgical approach is emphasized by most authors. We report a case of a large schwannoma of hypoglossal nerve origin in the upper neck in a 31-year-old male. Magnetic resonance imaging of the area demonstrated a $43 \times 39 \times 36 \mathrm{~mm}$ well-circumscribed mass with high and nonhomogeneous signal intensity on the right side of the upper neck. The lesion was successfully treated by extirpation, with no recurrence. The extracranial hypoglossal nerve sheath was as the origin of this tumor because the patient experienced remarkable disturbance of tongue motility after surgery.

\section{Keywords}

Hypoglossal Nerve, Benign Tumors, Schwannoma, Magnetic Resonance Imaging

\section{Introduction}

Schwannoma, a tumor of the peripheral nerve consisting of an abnormal proliferation of schwann cells, may be

"Corresponding author.

How to cite this paper: Morita, Y., Kawakita, C., Taya, M., Yuzaki, K., Kotani, T., Iwagami, T., Kobayashi, K. and Morita, N. (2014) Schwannoma of Hypoglossal Nerve Origin in the Upper Neck: Case Report and Review of the Literature. Open Journal of Stomatology, 4, 418-423. http://dx.doi.org/10.4236/ojst.2014.48056 
found in any part of the body. In more than $90 \%$ of cases, they present as vestibular schwannomas [1]. Schwannomas that arise from the hypoglossal nerve, a pure motor nerve, are very rare, accounting for only $5 \%$ of all nonacoustic intracranial schwannomas [2]. Due to their scarcity, early diagnosis of these lesions is difficult [3]. Magnetic resonance imaging (MRI) has become the routine imaging protcol for hypoglossal nerve neoplasms which are usually asymptomatic. Complete surgical resection is the best treatment for benign lesion such as a schwannoma. We present here a case of a large schwannoma of hypoglossal nerve origin in the upper neck.

\section{Case Report}

A 31-year-old male was referred to our outpatient clinic for a palpable lump on the right side of his neck. His past medical and family history were unremarkable. He was unaware of the lump when it was noticed during a routine annual staff medical check up. His face was symmetric with no lymphadenopathy, although a diffuse swelling was noted on the right side of the upper neck. Physical examination revealed a soft, smooth-surfaced mass in the right upper neck measuring $45 \times 40 \mathrm{~mm}$. MRI scan of the area demonstrated a $43 \times 39 \times 36 \mathrm{~mm}$ well-circumscribed mass with high and nonhomogeneous signal intensity on the right side of the upper neck, in the dorsal part of the submandibular glands (Figures 1(a)-(d)). The internal carotid artery and internal jugular vein were displaced dorsally, while the external carotid artery was displaced laterally at the level of its bifurcation fromthe carotid artery. Imaging diagnosis was aschwannoma or a paraganglioma. The results of fine needle aspiration biopsy of the mass performed before admission were inconclusive. Suspecting that this tumor was either aschwannoma or a paraganglioma, we decided to perform surgery.

Under general anesthesia, a cervical incision was made along the anterior border of the sternocleidomastoid muscle, with further dissection proceeding deep to the muscle. A yellowish-white, ovoid-shaped measuring $45 \times$ $40 \mathrm{~mm}$ was observed lying between the carotid sheath and the internal jugular vein. The superior end of the mass appeared in continuity with the hypoglossal nerve. Although the tumor was strongly adherent to the hypoglossal nerve, careful separation enabled its complete removal, with dissection and preservation of the hypoglossal nerve (Figure 2(a), Figure 2(b)). Pathological examination confirmed the diagnosis of benign schwannoma. Histological evaluation revealed a solid area of parallel spindle cells with eosinophilic cytoplasm (Antoni A pattern, Figure 3(a)), areas containing similar cells in a looser arrangement within myxoid ground substance (Antoni B pattern, Figure 3(b)), and blood vessels with hyalinized walls.

Post-operatively, the patient experienced remarkable disturbance of tongue motility, with the tongue body deviating to the right side on protrusion. Therefore, we diagnosed that the extracranial hypoglossal nerve sheath

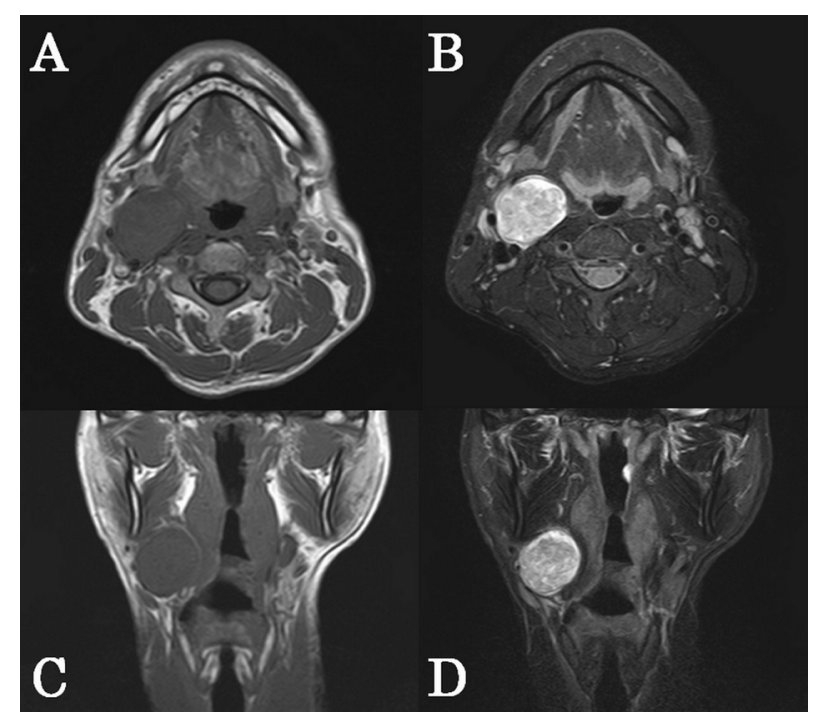

Figure 1. Magnetic resonance imaging: (a) Axial T1-weighted image, (b) axial T2-weighted image, (c) coronal T1-weighted image, and (d) coronal T2-weighted image showing a $38 \times 37$ $\times 28 \mathrm{~mm}$ well-circum-scribed mass in the dorsal part of the submandibular glands. 


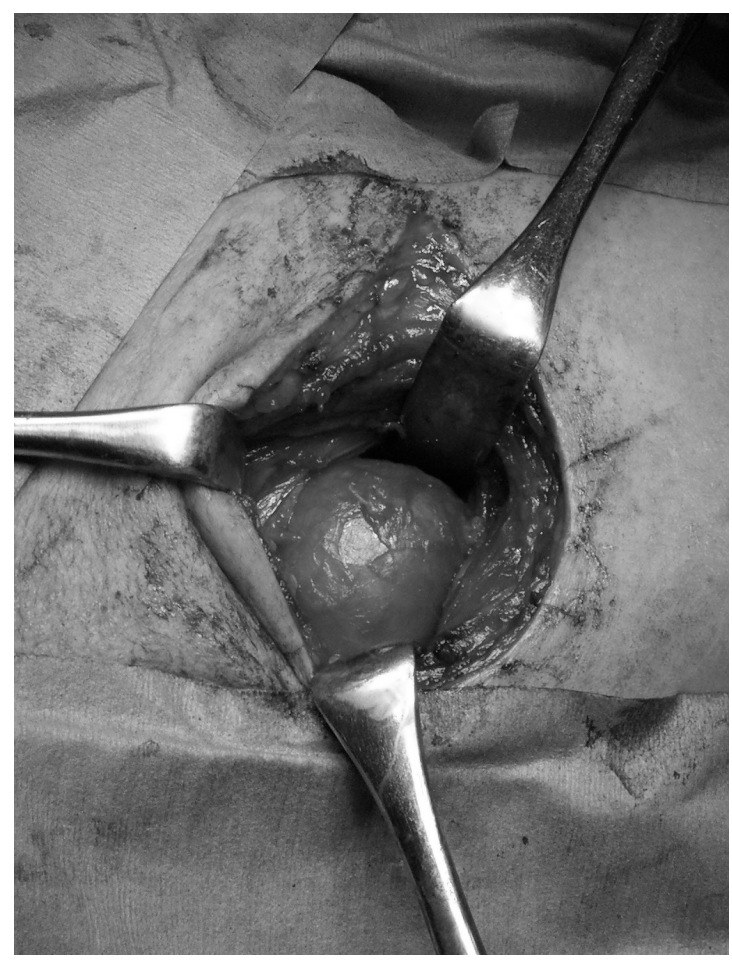

(a)

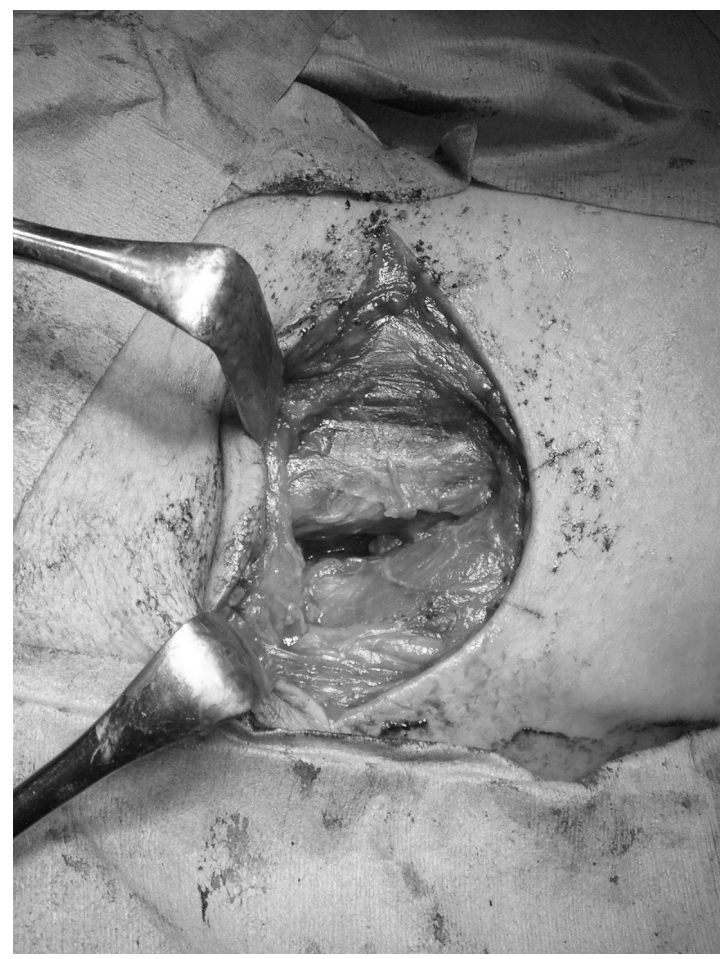

(b)

Figure 2. (a) Intraoperative photo showing a yellowish-white tumor lying between the carotid sheath and the internal jugular vein. (b) After removal of the tumor.
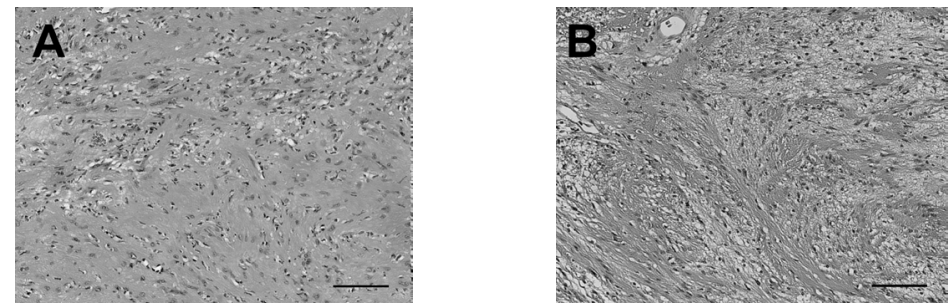

Figure 3. Photomicrographs showing (A) “Antoni A” and (B) “Antoni B” patterns (hematoxylin and eosin staining, bar: $100 \mu \mathrm{m}$.).

was the origin of this tumor. At follow-up 10 months after surgery, the patient was well, without any evidence of disease. Motility of the tongue was no longer disturbed.

\section{Discussion}

Schwannomas are rare peripheral nerve tumors, with about one third of them occurring in the head and neck region [4]. They originate from Schwann cells located in the sheaths of peripheral, cranial or autonomic nerves [5]. Many authors have reported that schwannomas occur at any age in both sexes, growing slowly and painlessly [5]-[8].

In the head and neck, schwannomas usually arise from the sensory divisions of cranial nerves, most commonly the vestibular and vagal nerves [8]. Hence, hypoglossal schwannomas are very rare because the hypoglossal nerve consists of only a motor component [8]. In previously report, the distribution of hypoglossal nerve of origins was $7 \%, 5 \%$, and 3\% (Table 1) [9]-[11]. The purely motor hypoglossal nerve emerges from the medulla oblongata between the pyramid and the olive, passes extracranially through the hypoglossal canal, and describes a wide ventral curve between the internal jugular vein and the internal carotid artery to the floor of the mouth. Hypoglossal schwannomas are commonly classified into the following four types based on their location 
Table 1. Distribution of extracranial head and neck schwannoma according to nerve of origin.

\begin{tabular}{cccc}
\hline Authors & R. Yasumatsu et al. & C. E. de Araujo et al. & D. Biswas et al. \\
cases & 27 & 20 & 31 \\
Vagus & 10 & 7 & 2 \\
Sympathetic trunk & 6 & 4 & 1 \\
Cervical plexus & 5 & 3 & 5 \\
Brachial plexus & 3 & 4 & 1 \\
Hypoglossal nerve & 2 & 1 & 0 \\
Accessory nerve & 1 & 0 & 1 \\
Glossopharyngeal nerve & 0 & 0 & 3 \\
Facial nerve & 0 & 0 & 0 \\
Lingual nerve & 0 & 0 & 9 \\
Not seen & 0 & 0 & \\
\hline
\end{tabular}

along the course of the nerve: type A, intradural tumors; type B, dumbbell-shaped tumors; type C, extracranial tumors; and type D, peripheral tumors [12]. The type D peripheral tumor is a tumor without osseous involvement. Most hypoglossal schwannomas have a dumbbell shape, involving both intracranial and extracranial segments of the hypoglossal nerve [13]. However, intracranial hypoglossal schwannomas are unusual [1]. The most distinguishing clinical findings of patients with hypoglossal nerve schwannomas are unilateral tongue atrophy and fasciculations [7] [14]. The differential diagnosis of tumors involving the hypoglossal canal includes chemodectoma, chordoma, meningioma, lymphoma and metastatic tumors [15]. In our case, the tumor was located in the upper neck, surrounded by the submandibular gland and carotid sheath, a space which is an unusual site for development of a schwannoma [16]. The tumor was eventually categorized as a type D schwannoma.

Pre-operative diagnosis of schwannomas is difficult because they do not present with neurological deficits. In our case, several differential diagnoses for tumors in the submandibular space needed to be considered, including benign pleomorphic adenoma, infectious disease, paraganglioma, branchial cleft cyst, malignant lymphoma and nodal metastases [7] [17]. Furthermore, due to their rarity, schwannomas are often not even included in the differential diagnosis. The usefulness of fine needle aspiration biopsy for diagnosis of schwannomas remains controversial. The majority of reports in the literature do not recommend open or needle biopsy for these masses [17]. There is general agreement concerning the importance of MRI in the pre-operative work-up of these patients, as it helps to define the diagnosis and evaluate the extent and relationship of the tumor with the surrounding tissue [18]. Carotid body paragangliomas are uncommon parapharyngeal space neoplasms that arise from chemoreceptive and sustentacular cells at the carotid bifurcation. These benign lesions display an insidious growth pattern [19]. Pleomorphic adenomas are the most common of all benign tumors of submandibular gland origin. They occur as slowly growing, solitary, well-demarcated masses with a capsule of variable thickness and completeness [6]. Carotid body paragangliomas and pleomorphic adenomas may be indistinguishable from schwannomas on MRI imaging features alone [6] [19] [20]. Despite the efficacy of CT and MRI in establishing a diagnosis for typical parapharyngeal space lesions, several imaging similarities between paragangliomas and schwannomas are confounding diagnosis. Both schwannomas and paragangliomas have variable signal intensity on T2-weighted images. Imaging principles frequently rely on the characteristic blood flow expected for each lesion, or on the anatomic origin of the neoplasm in question [19]. Surgical exploration is the only way to confirm the diagnosis. Total surgical resection is the gold standard treatment for such lesions, which include benign pleomorphic adenoma, infectious diseases, paraganglioma, branchial cleft cyst, malignant lymphoma, and nodal metastases, because they are well encapsulated and their separation is relatively easy while preserving the integrity of the nerve [21].

\section{Conclusion}

We report a large schwannoma of hypoglossal nerve origin in the upper neck. Although schwannomas in the 
upper neck are extremely rare, schwannoma should be included in the differential diagnosis when a well-localized mass is observed in this region, as in our case. In our opinion, total excision of the tumor via an external approach is the best treatment for this condition.

\section{Consent}

Written informed consent was obtained from the patient for publication of this Case report and any accompanying images. A copy of the written consent is available for review by the Editor-in-Chief of this journal.

\section{Competing Interests}

None declared.

\section{References}

[1] Rachinger, J., Fellner, F.A. and Trenkler, J. (2003) Dumbbell-Shaped Hypoglossal Schwannoma. A Case Report. Magnetic Resonance Imaging, 21, 155-158. http://dx.doi.org/10.1016/S0730-725X(02)00603-3

[2] Ho, K.L. (1981) Schwannoma of the Trochlear Nerve. Case Report. Journal of Neurosurgery, 55, 132-135. http://dx.doi.org/10.3171/jns.1981.55.1.0132

[3] Hoshi, M., Yoshida, K., Ogawa, K. and Kawase, T. (2000) Hypoglossal Neurinoma-Two Case Reports. Neurologia Medico-Chirurgica (Tokyo), 40, 489-493. http://dx.doi.org/10.2176/nmc.40.489

[4] Chang, S.C. and Schi, Y.M. (1984) Neurilemmoma of the Vagus Nerve. A Case Report and Brief Literature Review. Laryngoscope, 94, 946-949. http://dx.doi.org/10.1288/00005537-198407000-00016

[5] Diaz, D.D., Kennedy, K.S., Parker, G.S. and White, V.J. (1991) Schwannoma of the Submandibular Gland. Head \& Neck, 13, 239-242. http://dx.doi.org/10.1002/hed.2880130314

[6] Drevelengas, A., Kalaitzoglou, I. and Lazaridis, N. (1998) Sublingual Hypoglossal Neurilemmoma. Case Report. Australian Dental Journal, 43, 311-314. http://dx.doi.org/10.1111/j.1834-7819.1998.tb00179.x

[7] Chang, K.-C. and Leu, Y.-S. (2002) Hypoglossal Schwannoma in the Submandibular Space. Journal of Laryngology Otology, 116, 63-64. http://dx.doi.org/10.1258/0022215021910177

[8] Kawakami, R., Kaneko, T., Kadoya, M., Matsushita, T., Fujinaga, Y., Oguchi, K. and Kurashina, K. (2004) Schwannoma in the Sublingual Space. Dentomaxillofacial Radiology, 33, 259-261. http://dx.doi.org/10.1259/dmfr/93898716

[9] Yasumatsu, R., Nakashima, T., Miyazaki, R., Segawa, Y. and Komune, S. (2013) Diagnosis and Management of Extracranial Head and Neckschwannomas: A Review of 27 Cases. International Journal of Otolaryngology, 2013, Article ID: 973045. http://dx.doi.org/10.1155/2013/973045

[10] De Araujo, C.E.N., Ramos, D.M., Moyses, R.A., Durazzo, M.D., Cernea, C.R. and Ferraz, A.R. (2008) Neck Nerve Trunks Schwannomas: Clinical Features and Postoperative Neurologic Outcome. Laryngoscope, 118, 1579-1582. http://dx.doi.org/10.1097/MLG.0b013e31817b0702

[11] Biswas, D., Marnane, C.N., Mal, R. and Baldwin, D. (2007) Extracranial Head and Neck Schwannomas-A 10-Year Review. Auris Nasus Larynx, 34, 353-359. http://dx.doi.org/10.1016/j.anl.2007.01.006

[12] Nonaka, Y., Grossi, P.M., Bulsara, K.R., Taniguchi, R.M., Friedman, A.H. and Fukushima, T. (2011) Microsurgical Management of Hypoglossal Schwannomas over 3 Decades: A Modified Grading Scale to Guide Surgical Approach. Neurosurgery, 69, 121-140.

[13] Jia, G., Wang, Z. and Zhang, J. (2001) Diagnosis and Treatment of Hypoglossal Neurinoma. Chinese Medical Journal, 81, 1264-1265.

[14] Okura, A., Shigemori, M., Abe, T., Yamashita, M., Kojima, K. and Noguchi, S. (1994) Hemiatrophy of the Tongue Due to Hypoglossal Schwannoma Shown by MRI. Neuroradiology, 36, 239-240. http://dx.doi.org/10.1007/BF00588142

[15] Bartal, A.D., Djaldetti, M.M., Mandel, E.M. and Lerner, M.A. (1973) Dumb-Bell Neurinoma of the Hypoglossal Nerve. Journal of Neurology, Neurosurgery Psychiatry, 36, 592-595. http://dx.doi.org/10.1136/jnnp.36.4.592

[16] Sutay, S., Tekinsoy, B., Ceryan, K. and Aksu, Y. (1993) Submaxillary Hypoglossal Neurilemmoma. The Journal of Laryngology \& Otology, 107, 953-954. http://dx.doi.org/10.1017/s0022215100124892

[17] Colreavy, M., Lacy, P., Hughes, J., Bouchier-Hayes, D., Brennan, P., O’Dwyer, A.J., Donnelly, M.J., Gaffney, R., Maguire, A., O’Dwyer, T.P., Timon, C.V. and Walsh, M.A. (2000) Head and Neck Schwannomas-A 10 Year Review. The Journal of Laryngology \& Otology, 114, 119-124. http://dx.doi.org/10.1258/0022215001905058

[18] Chiofalo, M.G., Longo, F., Marone, U., Franco, R., Petrillo, A. and Pezzullo, L. (2009) Cervical Vagal Schwannoma. 
A Case Report. Acta Otorhinolaryngologica Italica, 29, 33-35.

[19] Lee, M.K., Sidell, D.R., Mendelsohn, A.H. and Blackwell, K.E. (2012) Hypoglossal Schwannoma Masquerading as a Carotid Body Tumor. Case Reports in Otolaryngology, 2012, Article ID: 842761. http://dx.doi.org/10.1155/2012/842761

[20] De Foer, B., Hermans, R., Sciot, R., Fossion, E. and Baert, A.L. (1995) Hypoglossal Schwannoma. Annals of Otology, Rhinology \& Laryngology, 104, 490-492.

[21] Piccirilli, M., Anichini, G., Fabiani, F. and Rocchi, G. (2007) Neurinoma of the Hypoglossal Nerve in the Submandibular Space: Case Report and Review of the Literature. Acta Neurochirurgica, 149, 949-952. http://dx.doi.org/10.1007/s00701-007-1154-9 
Scientific Research Publishing (SCIRP) is one of the largest Open Access journal publishers. It is currently publishing more than 200 open access, online, peer-reviewed journals covering a wide range of academic disciplines. SCIRP serves the worldwide academic communities and contributes to the progress and application of science with its publication.

Other selected journals from SCIRP are listed as below. Submit your manuscript to us via either submit@scirp.org or Online Submission Portal.
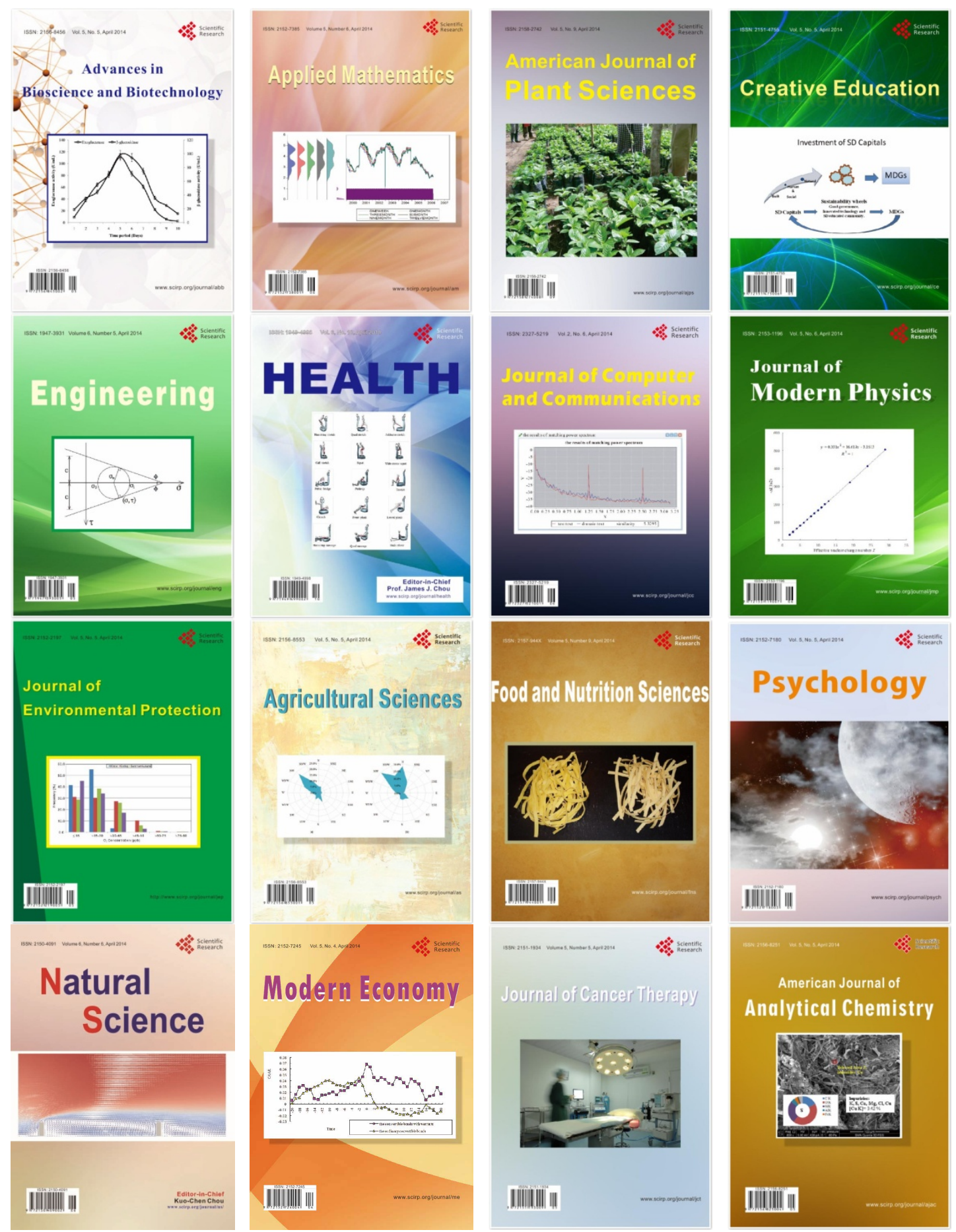